\title{
Katabatic winds and piteraq storms: observations from the Greenland ice sheet
}

\author{
Dirk van As, Robert S. Fausto, Konrad Steffen and the PROMICE project team*
}

In 2007 the Programme for Monitoring the Greenland Ice Sheet (PROMICE) was initiated to observe and gain insight into the mass budget of Greenland ice masses. By means of in situ observations and remote sensing, PROMICE assesses how much mass is gained as snow accumulation on the surface versus how much is lost by iceberg calving and surface ablation (Ahlstrøm et al. 2008). A key element of PROMICE is a network of automatic weather stations (AWSs) designed to quantify components of the surface mass balance, including the energy exchanges contributing to surface ablation (Van As et al. 2013).

The use of these AWS observations is not limited to studies of ice-sheet mass balance. PROMICE contributes to CryoNet (www.globalcryospherewatch.org/cryonet), the core network of surface measurement sites of the World Meteorological Organization (WMO) Global Cryosphere Watch. By real-time delivery through WMO, PROMICE observations contribute to improve both operational forecasting and climate analysis in the data-sparse Arctic. The Greenlandic population, highly dependent on accurate forecasting of weather conditions, benefits directly from these real-time observations. For instance, extreme surface wind speeds are a high-risk element in Greenland. The third-highest wind speed observed at the surface of the Earth $(93 \mathrm{~m} / \mathrm{s}$ or 333 $\mathrm{km} / \mathrm{h}$ ), was recorded in a 8-9 March 1972 storm at Thule in North-West Greenland (Stansfield 1972).

In this paper, we discuss the extent to which the Greenland ice sheet generates its own near-surface wind field. We use PROMICE data to gain insight into the interaction between air temperature, radiation and gravity-driven katabatic winds. We focus on a particularly powerful spring storm in 2013 that contributed to a fatality on an ice-sheet ski traverse attempt (Linden 2013).

\section{Weather stations on the Greenland ice sheet}

The original PROMICE network consisted of fourteen AWSs in seven ablation regions of the Greenland ice sheet, with each region monitored by a lower (L) and an upper (U) elevation station (Fig. 1; Ahlstrøm et al. 2008). PROMICE has collaborated logistically and financially with other projects in the regions of the TAS, QAS, NUK and KAN stations, leading to the installation of eight additional AWSs. The PROMICE

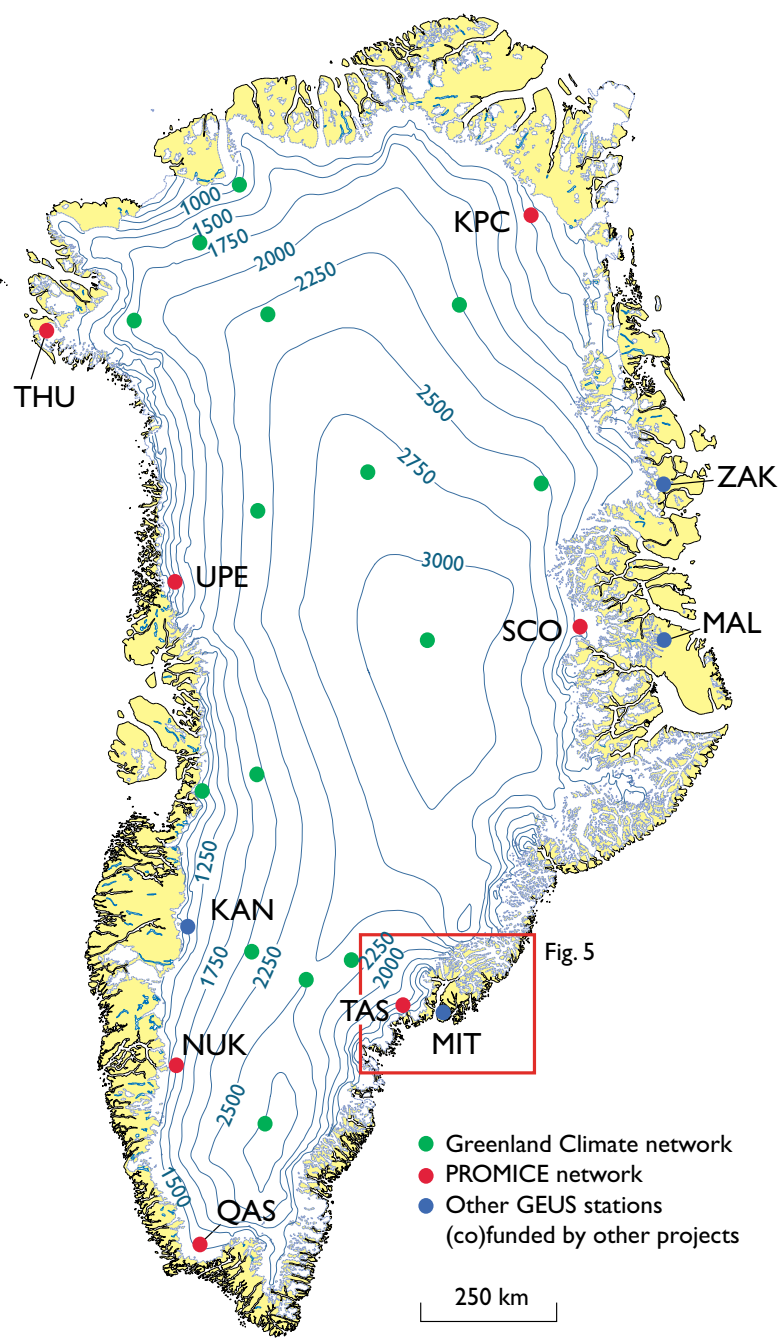

Fig 1. Map of Greenland showing the locations of automatic weather stations on the ice sheet and on local ice caps.

* Andreas P. Ahlstrøm, Signe B. Andersen, Morten L. Andersen, Jason E. Box, Charalampos Charalampidis, Michele Citterio, William T. Colgan, Karen Edelvang, Signe H. Larsen, Søren Nielsen, Martin Veicherts and Anker Weidick 

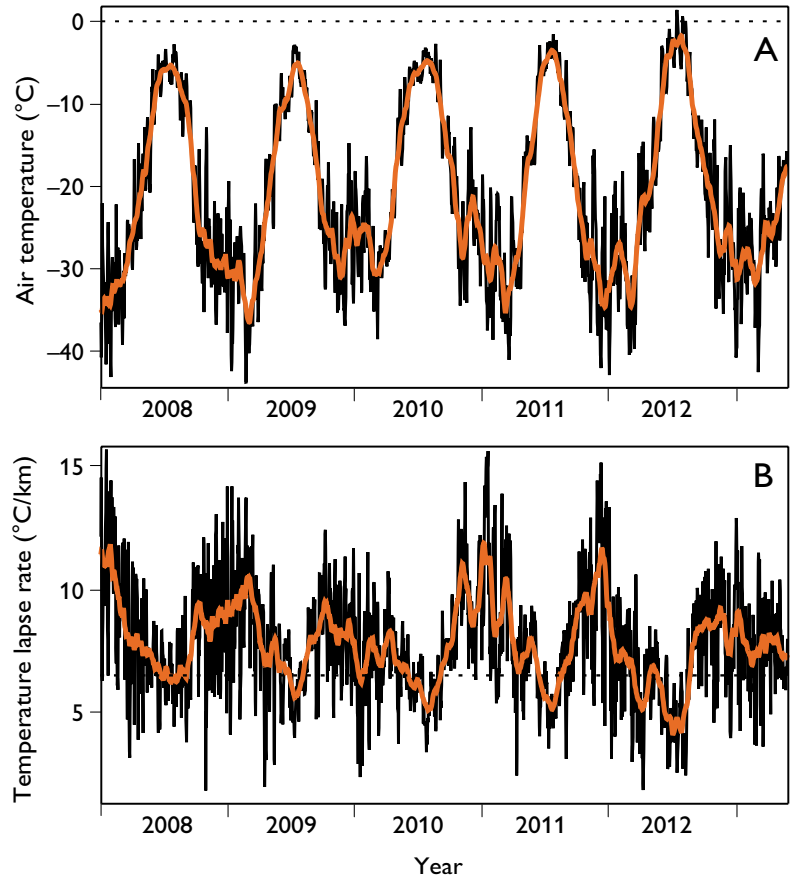

Fig. 2. A: Daily average (black) and 31-day average (red) air temperature over the Greenland ice sheet as determined from interpolated weather station observations from the GC-Net and PROMICE network. B: Same, but vertical near-surface temperature lapse rates. The dashed line shows a lapse rate of $6.5^{\circ} \mathrm{C} / \mathrm{km}$ above which air masses are increasingly unstable.

AWS sites have been selected to complement the Greenland Climate Network (GC-Net), which chiefly monitors the icesheet accumulation area (Steffen et al. 1996).

Continuous PROMICE AWS observations include: air temperature (c. $2.7 \mathrm{~m}$ above surface), barometric pressure, air humidity, wind speed and direction (c. $3.1 \mathrm{~m}$ above surface) as well as down- and upward solar (shortwave) and terrestrial (longwave) radiation. The AWSs also record temperature profiles in the upper $10 \mathrm{~m}$ of the ice, GPS-derived location and diagnostic parameters such as station tilt angles. A pressure transducer and two sonic rangers measure snow and icesurface height change associated with ablation and accumulation (Fausto et al. 2012). All data and metadata including sensor specifications are available at www.promice.org.

Here, we use averaged values of air temperature, wind speed and direction, and radiation components. Single wind measurements have an uncertainty of $0.3 \mathrm{~m} / \mathrm{s}$ and $3^{\circ}$ (Van As 2011) and are not adjusted for shifts in tilt, rotation or measurement height as this does not impact the outcome of this study. We also combine GC-Net and PROMICE temperature data to give the most complete observed meteorological depiction of the Greenland ice sheet currently possible. We calculated the daily average near-surface air temperature across the ice sheet between 2008 and 2013 by means of inverse-distance interpolation between as many as 32 AWSs that operated on a given day. We also determined the daily average vertical near-surface air-temperature lapse rate by means of a linear least-squares fit to all available data.

\section{Atmospheric temperature and stability}

The average near-surface air temperature over the Greenland ice sheet has a distinct annual cycle with minimum (winter) values between $-20^{\circ} \mathrm{C}$ and $-40^{\circ} \mathrm{C}$ (Fig. $2 \mathrm{~A}$ ). During the relatively short summer, temperatures are often around $-5^{\circ} \mathrm{C}$ and are less variable due to (1) reduced cyclonic activity and (2) surface melting over large parts of the ice sheet. The latter is a moderating factor because near-surface temperatures are limited to near freezing. Since 2008, ice-sheet average air temperatures above $0^{\circ} \mathrm{C}$ have only been recorded on five days (11-13 and 28-29 July 2012) during which surface melting occurred over nearly the entire ice sheet (e.g. Nghiem et al. 2012).

The average near-surface air-temperature lapse rate over the ice sheet exhibits a reversed cyclicity as compared to air temperature with winter values often exceeding a $10^{\circ} \mathrm{C}$ decrease per vertical kilometre (Fig. 2B). Assuming a textbook value of a $6.5^{\circ} \mathrm{C} / \mathrm{km}$ free-atmospheric lapse rate to be representative
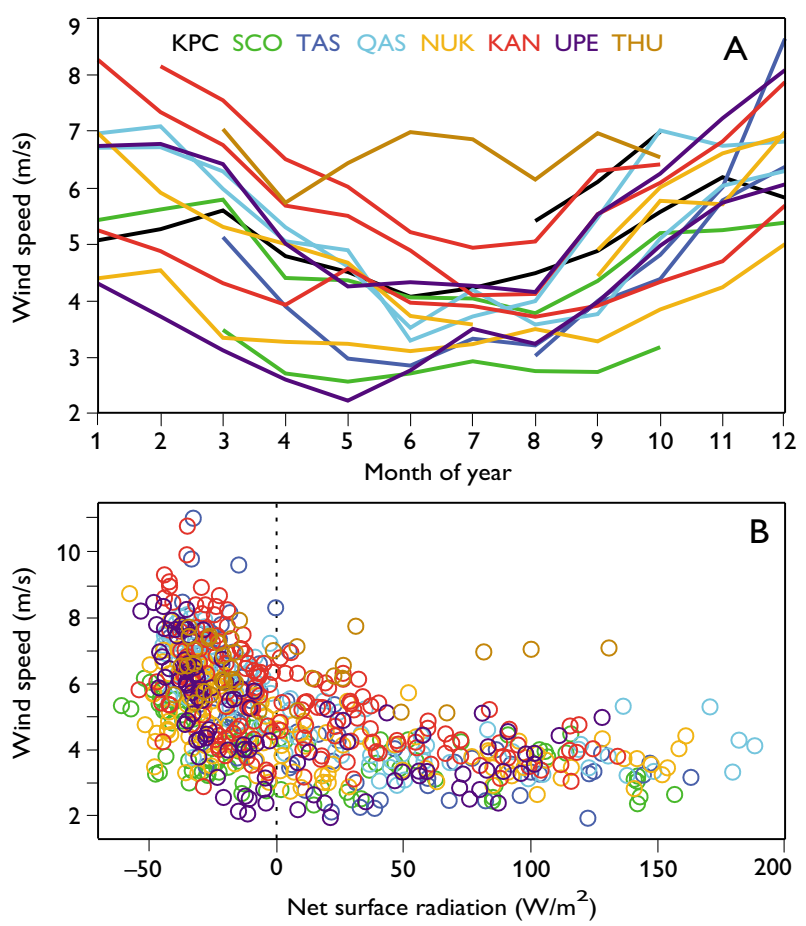

Fig. 3. A: The average annual cycle in wind speed at the PROMICE sites. Lines are drawn for each weather station, but only if three years of good data are available. B: The monthly average wind speed versus the net (shortwave + longwave) radiation budget. For locations of the stations see Fig. 1. 
of the threshold between stable and unstable conditions over Greenland, this suggests that the near-surface atmosphere is commonly less buoyant (denser) at higher elevations than air at lower elevations. In a free atmosphere such a density difference over a few vertical kilometres would trigger an immediate adjustment through convection. Over the large horizontal scale of the Greenland ice sheet, the actual density gradients are roughly two orders of magnitude smaller, which adds insignificantly to the force balance. Figure $2 \mathrm{~B}$ illustrates that during winter, the high elevation interior of the ice sheet cools more than lower elevation regions near the margin. As a result, the shallow (c. $100 \mathrm{~m}$ thick) stable atmospheric boundary layer that blankets the ice sheet attains an even larger temperature deficit compared to the free atmosphere at high elevation in winter. The larger this temperature deficit relative to the free atmosphere, the larger the density difference relative to the free atmosphere, and thus the larger the gravitational acceleration of the shallow boundary layer. This katabatic force increases linearly with increasing surface slope.

\section{Katabatic winds}

Winds over the Greenland ice sheet are strongest in winter (e.g. Steffen \& Box 2001), as observed at every PROMICE AWS (Fig. 3A). While part of this increase is due to lower wintertime pressure and more frequent passage of cyclonic systems, the primary cause of stronger winter winds is surface radiative cooling. This well-known forcing mechanism of katabatic wind is apparent from stronger winds at more negative surface net radiation (Fig. 3B) and the strong correlation between the directions in slope and wind (see below). A negative radiation budget is common during winter due to little or no solar radiation at high latitudes when the upward emission of long-wave terrestrial radiation exceeds downward atmospheric radiation at the surface.

The wind regimes over the ice sheet do differ between regions. Winds are stronger at the higher-elevation AWSs due to the larger radiative cooling of the surface (provided a surface slope is present). The highest monthly-mean wind speed values in Fig. 3B were recorded at KAN_M and KAN_U (1270 and $1840 \mathrm{~m}$ a.s.l., red), and TAS_U and TAS_A (570 and $900 \mathrm{~m}$ a.s.l., blue).

\section{Piteraq storms}

The wind regimes at KAN and TAS are shown in a case study of the 2012/2013 winter (Fig. 4). Figure 4A illustrates that low-wind winter conditions are rare at KAN_U, PROMICE station at highest elevation. Figure $4 \mathrm{~B}$ shows the dominant katabatic nature of winter winds. Nearly all measure- ments from KAN_U show the wind to blow from upslope direction (c. $90^{\circ}$, east), albeit deflected to the right (c. $135^{\circ}$, south-east) by the Coriolis effect due to the Earth's rotation. Typically, wind speeds at TAS_U are lower (but still nonzero) due to the weaker radiative cooling at lower elevation. Katabatic forcing also dominates here, given the persistent non-zero winds originating from the upslope direction of $c$. $0^{\circ}$ (north) and more westerly directions due to Coriolis forcing. The major difference between the two data series in Fig. 4 is the frequency of strong wind events exceeding c. $20 \mathrm{~m} / \mathrm{s}$, which are more common in the TAS region. In the strongest storms, the wind direction pivots towards the regional freeatmospheric flow (Fig. 4B).

These storms are known in Greenland as piteraqs, and build up momentum due to the alignment of katabatic and large-scale (geostrophic) forcing (Oltmanns et al. 2014). These notorious storms have repeatedly caused severe damage to the towns such as Tasiilaq. The piteraq on 27 April 2013 (Fig. 4A), which jeopardised a sport expedition on the ice sheet (Linden 2013), was exceptionally strong at TAS_U in the context of the 2008 to 2013 PROMICE observational period, with 10-minute average wind speeds exceeding $42 \mathrm{~m} / \mathrm{s}(150 \mathrm{~km} / \mathrm{h})$. During this event, four persons (C. Charalampidis, W.T. Colgan, H. Machguth and D. van As)
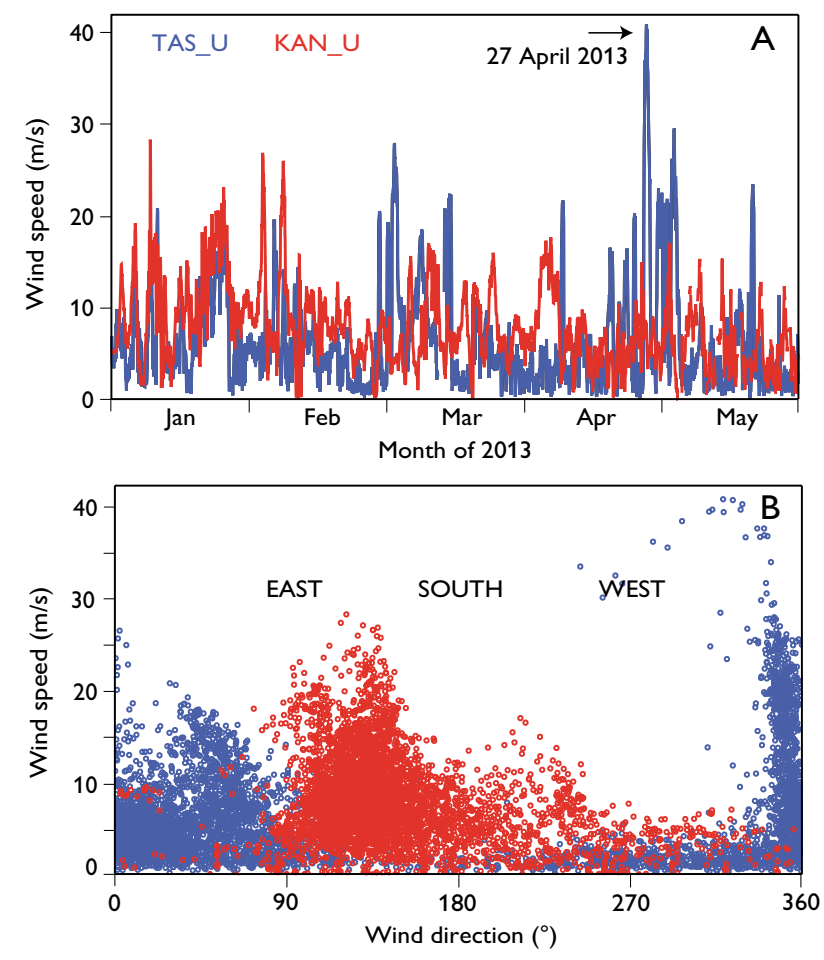

Fig. 4. A: Hourly average wind speed at TAS_U and KAN_U weather stations. The piteraq on 27 April 2013 is clearly visible in the TAS_U observations. B: Same, but wind speed plotted versus wind direction for the period from October 2012 to May 2013. 


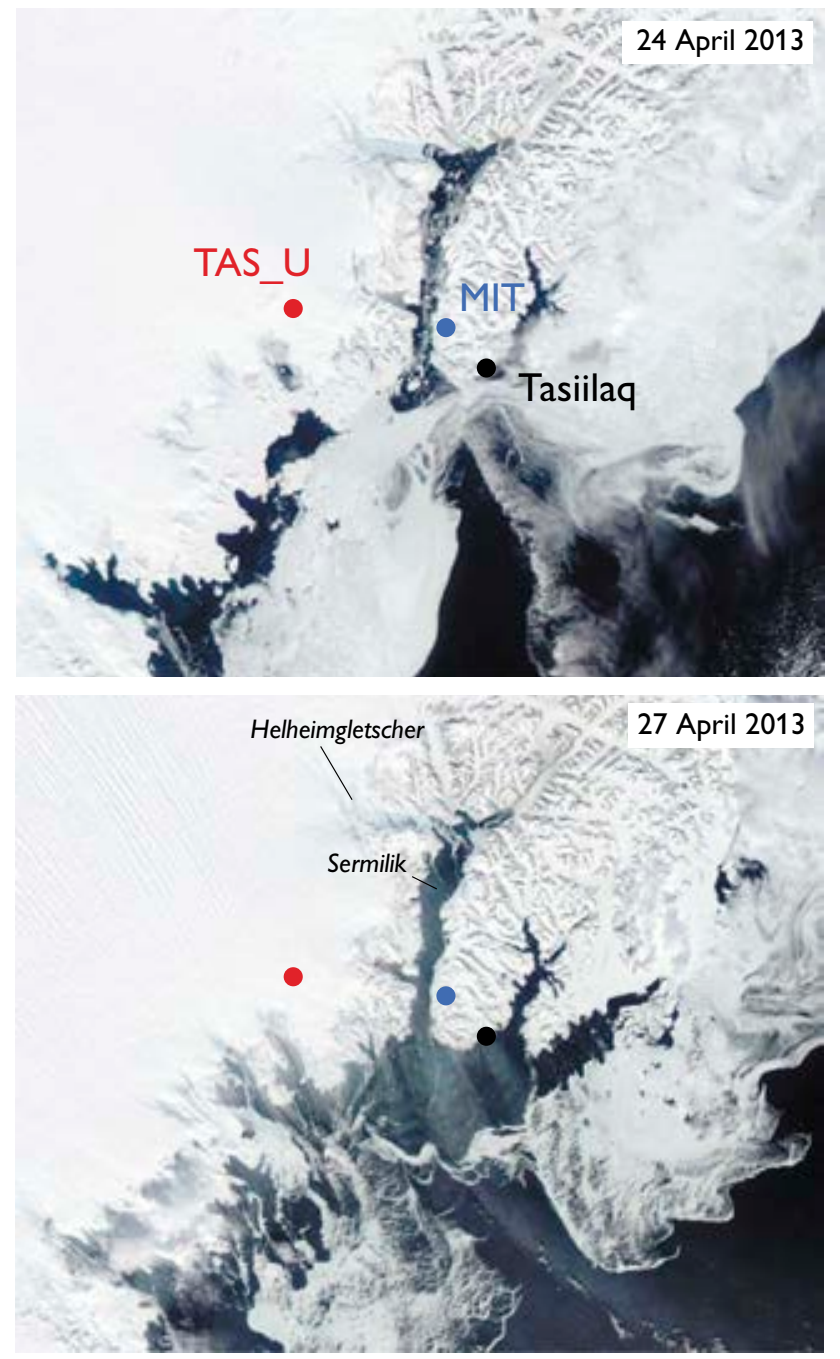

Fig. 5. MODIS satellite images of the Tasiilaq region of South-East Greenland on 24 and 27 April 2013, before and during a strong piteraq event. For location, see Fig. 1.

from the Geological Survey of Denmark and Greenland were in the field at KAN_U, and although they experienced wind speeds approximately one third of those at TAS_U (c. $300 \mathrm{~km}$ to the east) the white-out and heavy snowdrift yielded conditions too dangerous for them to leave shelter.

Satellite images from the 2013 piteraq event show that a large region was affected (Fig. 5). The striping on the ice sheet in the top left corner of the lower image shows the wind direction with snow transported toward and past the ice sheet margin. Large areas of sea and ford ice disintegrated, and the 5-13 km wide Sermilik fjord, into which Helheimgletscher calves, was cleared of ice.
Clearly, katabatic winds and especially the piteraqs, have a large impact on the ice sheet and its immediate surroundings. Given increasing commercial activity around the periphery of the Greenland ice sheet, there is a growing impetus for understanding these winds and their response to climate change. Regional atmospheric model projections until the year 2100 suggests that while climate change will likely result in weaker winds in Greenland's flat interior, stronger winds may occur in steeper regions around the ice sheet periphery (Gorter et al. 2013).

\section{Acknowledgements}

PROMICE is funded by the Danish Ministry of Climate, Energy and Building and is operated by the Geological Survey of Denmark and Greenland. Several weather stations are (co)funded by the Greenland Analogue Project, the REFREEZE project and the Greenland Climate Research Centre.

\section{References}

Ahlstrøm, A.P. \& the PROMICE project team 2008: A new programme for monitoring the mass loss of the Greenland ice sheet. Geological Survey of Denmark and Greenland Bulletin 15, 61-64.

Fausto, R.S., Van As, D., Ahlstrøm, A.P. \& Citterio, M. 2012: Assessing the accuracy of Greenland ice sheet surface ablation measurements by pressure transducer. Journal of Glaciology $\mathbf{5 8}$ (212), 1144-1150.

Gorter, W., van Angelen, J.H., Lenaerts, J.T.M. \& van den Broeke, M.R. 2013: Present and future near-surface wind climate of Greenland from high resolution regional climate modelling. Climate Dynamics $\mathbf{4 2}$, 1595-1611.

Linden, M. 2013: Greenland death: how $100 \mathrm{mph}$ ice storms can blow in without warning. The Independent, 1 May 2013. London, UK.

Nghiem, S.V., Hall, D.K., Mote, T.L., Tedesco, M., Albert, M.R., Keegan, K., Shuman, C.A., DiGirolamo, N.E. \& Neuman, G. 2012: The extreme melt across the Greenland ice sheet in 2012. Geophysical Research Letters 39, L20502.

Oltmanns, M., Straneo, F., Moore, G.W.K. \& Mernild, S.H. 2014: Strong downslope wind events in Ammassalik, Southeast Greenland. Journal of Climate 27, 977-993.

Stansfield, J. 1972: The severe Arctic storm of 8-9 March 1972 at Thule Air Force Base, Greenland. Weatherwise 25, 228-233.

Steffen, K. \& Box, J.E. 2001: Surface climatology of the Greenland Ice Sheet: Greenland climate network 1995-1999. Journal of Geophysical Research: Atmospheres 106(D24), 33951-33964.

Steffen, K., Box, J.E. \& Abdalati, W. 1996: Greenland climate network: GC-Net. In: Colbeck, S.C. (ed.): Glaciers, ice sheets and volcanoes: a tribute to Mark F. Meier. CRREL special Report 96-27, 98-103.

Van As, D. 2011: Warming, glacier melt and surface energy budget from weather station observations in the Melville Bay region of northwest Greenland. Journal of Glaciology 57(202), 208-220.

Van As, D., Fausto, R.S., Colgan, W.T., Box, J.E. \& PROMICE project team 2013: Darkening of the Greenland ice sheet due to the melt-albedo feedback observed at PROMICE weather stations. Geological Survey of Denmark and Greenland Bulletin 28, 69-72.

\footnotetext{
Authors' addresses

D.v.A. and others, except K.S., Geological Survey of Denmark and Greenland, Øster Voldgade 10, DK-1350 Copenhagen K, Denmark. E-mail: dva@geus.dk K.S., Swiss Federal Institute for Forest, Snow and Landscape Research (WSL), Zürcherstrasse 111, CH-8903 Birmensdorf, Switzerland.
} 